\title{
EL IMPACTO DE LA TECNOLOGÍA EN EL ÁMBITO SOCIAL Y EN LA DESIGUALDAD \\ (The impact of technology in the social sphere and inequality)
}

Astrid Ximena Cortés Lozano' Investigadora

Grupo de investigación GIBS - UNIMINUTO Bogotá Sur astrid.cortes@uniminuto.edu

El presente artículo expone la relación entre tecnología, impacto social y desigualdad en los actuales escenarios, donde el hombre se ha encaminado en un "viaje de no retorno", en el que todas sus actividades, incluso sus propias relaciones sociales, se encuentran mediadas por la tecnología, situación que ocasiona que la brecha social aumente y que el acceso a los reales recursos, no solo de tipo informacional, sino también económicos, educativos, etc., sea una causa real y evidente del distanciamiento entre unos y otros.

Palabras clave: Impacto tecnológico, Desigualdad, Sociedad, Exclusión, Inclusión.

\section{Abstract}

This paper presents the relationship between technology, the social impact of and inequality in current scenarios such as those in humanity that have embarked on a "journey of no return." All activities connected to technology, even social relations are mediated by technology; for example, the social gap that increases mirrors actual resource access, not limited to information, but also economic and educational to be an actual and evident cause of distancing the social classes.

Keywords: Technological impact; Inequality; Society; Exclusion; Inclusion. 


\section{INTRODUCCIÓN}

C uando se habla de desigualdad social se está denunciando un grave problema que afecta todas las esferas de la sociedad. Cuando una nación, en este caso concreto Colombia, no es capaz de garantizar las mismas oportunidades a todos sus habitantes y el acceso real a todos los derechos, cualquiera sea su clase, es imposible hablar de un colectivo que apunte al bienestar social.

En esta dirección, es deber del Estado encontrar caminos para disminuir la brecha social entre "pudientes" y "no pudientes", y garantizar el respeto por todos los derechos del hombre; y que mejor forma de intentar encontrar dichos caminos que a través del actual momento coyuntural; un momento histórico para nuestra Nación, cuando el desarrollo tecnológico aparece como un halo de esperanza, de unidad, de no exclusión y, sobre todo, de igualdad.

Es por ello que, en esta oportunidad, la revista Inclusión \& Desarrollo presenta una reflexión sobre el tema, que se compone de una serie de aspectos tendientes a dilucidar la relación actual entre tecnología y sociedad:

\section{IMPACTO DE LA TECNOLOGÍA}

\section{DE LA INFORMACIÓN EN LA SOCIEDAD}

El impacto de la tecnología en las sociedades modernas ha ocasionado que surjan nuevas divisiones culturales y sociales entre las personas que tienen acceso a ella. Estos cambios se originan tanto entre países (adelantados y subdesarrollados) como en el seno de las mismas naciones, debido a que no todas las personas que conviven en un mismo territorio tienen iguales oportunidades de utilizar estas herramientas. Cabe indicar que una muy pequeña porción de la humanidad tiene acceso a las tecnologías y quienes forman parte de ella se actualizan más y más en estas habilidades, generando un bache abismal, dado que mientras unos avanzan a grandes velocidades, el resto ni siquiera "despega". "Semejante distribución tal vez suene con- vincente para quien reparte el pastel, pero no para los grupos humanos sobre cuyo destino se decide sin que tengan oportunidad de participar en la decisión (...) la división del mundo en dos humanidades, una que se mueve hacia la sociedad ciberespacial, $y$ otra que vegeta en una economía de subsistencia" (Hernández-Baqueiro, 2003).

Pero, estos adelantos tecnológicos no solo cambian las relaciones sociales, sino que repercuten también en las relaciones económicas mundiales; esto se observa, en el hecho de que no obstante el comercio electrónico esté ganando más y más adeptos, se aleja cada vez más de la gran mayoría de la población.

La educación debe constituirse en un proceso de gran importancia en el proceso de inclusión social de las nuevas tecnologías; sin embargo, aquí surge otro problema debido a que la inversión económica que deberían hacer la mayoría de países, contrasta fuertemente y de manera abrupta con la que pueden realizar. Es responsabilidad de los estados "apretar el paso" para que esta inversión en educación (poca o mucha) llegue a todos los ciudadanos. Hay que recordar que las nuevas tecnologías no buscan reemplazar las habilidades del hombre, ni al hombre mismo; más bien deben servir como herramientas que apoyen las actividades humanas, pensando en un mayor beneficio para la población, de manera eficiente, eficaz, rápida y productiva.

\section{Cambios en las relaciones humanas}

Todas las brechas sociales que se mencionan en el punto anterior se explican perfectamente, debido a que las relaciones sociales nacen de las relaciones interpersonales (si es que no son el mismo asunto).

Esta brecha entre los "enchufados" y los "desenchufados" imposibilita desarrollar relaciones humanas confiables y a un mismo nivel entre las personas, incluso en un mismo hogar, como en mi caso, donde mis padres conocen muy poco de la tecnología, mientras que mi 
hermano y yo llevamos "años luz" de ventaja; supongo que lo mismo sucederá entre mi hijo y yo (depende de mí, con una constante actualización, impedir que esta brecha se presente).

Debe haber una relación estrecha, constante y creciente no solo en las relaciones interpersonales, sino también entre conglomerados, sobre todo los que tienen poder decisorio en los países, como los gobiernos, las universidades y las empresas (que son los que deben liderar este cambio tan brusco que nos han impuesto las potencias -USA-).

\section{AsPeCTOS ÉTICOS QUE CONLLEVA EL USO DE LA TECNOLOGÍA}

Uno de los aspectos éticos que se debe considerar con la inclusión de las tecnologías en las sociedades modernas es el que los gobiernos deben asegurar, a la comunidad que los encumbró, la estabilidad laboral; es decir, deben garantizar que las tecnologías, y con ellas el exceso de computación y automatización, no vayan a dejar sin posibilidades de trabajo a las personas. Con esto se evitaría el incremento del desempleo, el cual no solo se deben a la inclusión de las nuevas tecnologías, sino también a otros factores. "En el mundo actual, la condición del desempleado puede ser sumamente angustiosa. El desempleo no siempre se puede tomar tranquilamente como un estado transitorio en tanto que se adquiere la capacitación para ocupar una nueva posición en el aparato productivo" (HernándezBaqueiro, 2003).

Otro aspecto ético que se debe tener en cuenta, es que quienes diseñan y elaboran estas herramientas tecnológicas no suban excesivamente sus precios, para que de esta forma las personas que no tengan muchos recursos económicos puedan tener acceso a estas "maravillas". El fin último de un invento o un producto no es lucrarse a costa de los demás, sino compartir este descubrimiento o adelanto y tener el reconocimiento social y humano. Eso es lo que verdaderamente importa y lo que, por lo menos a mí, me motiva de verdad. Otro aspecto ético para considerar es el que quienes desa- rrollan estas herramientas tecnológicas tengan la responsabilidad social y humana de reconocer sus errores, porque suele suceder que a veces responsabilizan de sus efectos nocivos al mal uso que los usuarios hacen de la herramienta y olvidan que quizás ellos también han tenido injerencia con su inapropiada guía en el manejo del producto.

Las tecnologías de la información han abierto al mundo, a través de la Internet, la posibilidad de compartir documentos (colgar) y obtenerlos (descargar) de manera fácil con un simple buscador. Es aquí cuando el valor ético de las personas adquiere vital importancia; desde el niño que está en la escuela hasta el alto ejecutivo, deben estar inscritos en una cultura ética que implique respetar el concepto de propiedad intelectual, evitando plagiar las ideas o documentos publicados en Internet por los demás. Mucha gente se rehúsa a publicar en la red por temor al plagio y "ni para qué hablar de las ideas patentables". Las empresas también deben practicar una ética adecuada en sus relaciones, con ellas mismas, con sus empleados, con la sociedad y con el medio ambiente. Deben brindar igualdad de oportunidades, y operar con criterios de tolerancia, pluralismo, legalidad y solidaridad.

No debería haber nadie más ético que los políticos: dejarse de tanto bla bla bla para asumir responsablemente las funciones que se les ha delegado, las cuales se inmediatizan con la inclusión de las tecnologías de la información como consecuencia de la globalización y el neoliberalismo abierto, impuesto en Colombia por el expresidente César Gaviria.

El ámbito social y económico, con las nuevas tecnologías, está dejando a un lado lo verdaderamente importante: la cultura y el crecimiento del hombre en sus valores y espíritu. En esta época tecnológica, cuando los valores se han perdido considerablemente y cuando con solo hacer un clic se tiene acceso a cualquier parte y situación del mundo, la familia y sus valores deben constituirse en una herramienta que ayude a defender a los niños de tanta "porquería". Debemos orientarlos, desde el hogar para que 
tengan la capacidad de enfrentarse adecuadamente al mundo, real y virtual.

\section{USOS CORRECTOS E INCORRECTOS}

\section{DE LA TECNOLOGÍA}

Se deben dar un uso correcto a la tecnología a través del diseño adecuado de sus herramientas, ya que de otro modo se pueden ocasionar daños irreparables a la humanidad. De este modo:

- El uso correcto de las tecnologías de información puede ayudar a la humanidad a llegar a espacios insospechados de desarrollo, pero su uso incorrecto puede sumirnos en la propia desgracia de nuestra opulencia: tenerlo todo, pero a la vez no tener nada.

- El uso incorrecto e inadecuado de las tecnologías ocasiona dos graves problemas que nos apartan socialmente: la masificación y el consumismo.

- El uso incorrecto de las tecnologías fortalece a los Estados Unidos y su capitalismo, convirtiéndole en un monstruo supremo e imparable que decide todo lo que rige a las personas... lo mejor sería que nos abstengamos de conectarnos para quitarle un poco de poder: si la red no mostrara determinadas informaciones, Estados Unidos no se enteraría de muchas otras.

- El uso correcto de la tecnología puede ayudar a que las familias se vuelvan a unir. Es el caso de los padres que trabajan todo el día, pueden estar en contacto permanente con sus hijos, en las escuelas y colegios, gracias al Internet y a sus herramientas. "Los nuevos medios prometen fortalecer la familia al volver a trasladar al hogar muchas actividades familiares dispersas por la sociedad industrial" (Tapscott, 1988).

- El uso correcto de la tecnología contribuye a los procesos de enseñanza-aprendizaje y permite a las personas actualizarse en sus estudios mientras trabajan y se divierten.

- El uso incorrecto de la tecnología crea monstruos de gran envergadura, como es el caso de la pornografía.
RIESGOS DEL USO INTENSIVO

Y DEPENDENCIA EXCESIVA DE LA

\section{TECNOLOGÍA}

Uno de los riesgos del uso intensivo y dependencia excesiva de la tecnología consiste en que las personas se vuelven apáticas (nada les sorprende), solitarias y dependientes de las máquinas, se incrementa la pereza dado que todo se consigue con solo un clic (por eso abundan las personas obesas y graves enfermedades asociadas). Si se dedica mucho tiempo a la tecnología, se corre el riesgo de apartarse de la sociedad misma, lo que puede ocasionar trastornos severos de comportamiento, e incluso la muerte, porque el ser humano es una persona social. Existen cosas que por mucha tecnología que haya no se pueden reemplazar, como es el amor, el ejercicio físico y demás, que al no estar presentes, y gracias al exceso tecnológico, hacen de las personas, autómatas.

Es que el uso excesivo de la tecnología no solo afecta a las personas, sino a las sociedades que constituyen. Si se suman más y más individuos adictos tecnológicamente tendremos ciudades, pueblos y países sin corazón y apáticos ante lo que sucede a su alrededor, dado el poco valor que estas personas le asignarán a lo verdaderamente importante... una vida plena, libre y tranquila.

Como se puede apreciar, la relación tecnología y sociedad es un asunto de interés general, pues si bien es un camino para poder reducir la brecha imperante, no es el único, pues cada sector social debe aportar en dicha reducción, asimilando de la mejor forma este momento crucial del desarrollo, pues solo de esta manera se podrán generar verdaderas y viables posibilidades de inclusión, cuyo principal garante de su cumplimiento tiene que ser el propio Estado y el principal actor de una nueva nación, basada en el derrotero de la Tecnologías de la Información y la Comunicación -TIC, tiene que ser la misma población 


\section{Referencias bibliográficas}

Hernández-Baqueiro, A. (2003). Modernidad y tecnología o de la brecha entre cultura y tecnología en las sociedades modernas. Lecturas en Humanidades: Sociedad y Tecnología I (10) I5-32.

Tapscott, D. (1988). La generación-N y el aprendizaje (Trad. García A.). Bogotá D.C.: McGraw-Hill. 